High production costs and perceived declines in soil quality due to agricultural intensification have led to recent interest in conservation tillage production practices. We conducted field experiments in Five Points in 1997 and 1998 to evaluate the effectiveness of maintaining a cover crop mulch on the soil surface in a no-till system compared to a standard tillage system for conserving soil moisture and improving water infiltration and other soil physical properties in a furrow-irrigated tomato field. Soil water content did not differ among treatments in 1997, but was higher under no-till cover crop mulches than conventionally tilled plots during the 1998 growing season. Soil carbon was increased more than $8 \%$ and more earthworms were found under no-till mulches relative to the conventionally tilled plots in the second year of the study. Soil compaction was lower in no-till treatments, especially at the 1-to-2-foot depth. In this study, furrows were swept clean and therefore furrow irrigation did not constitute a limitation to this no-till system.

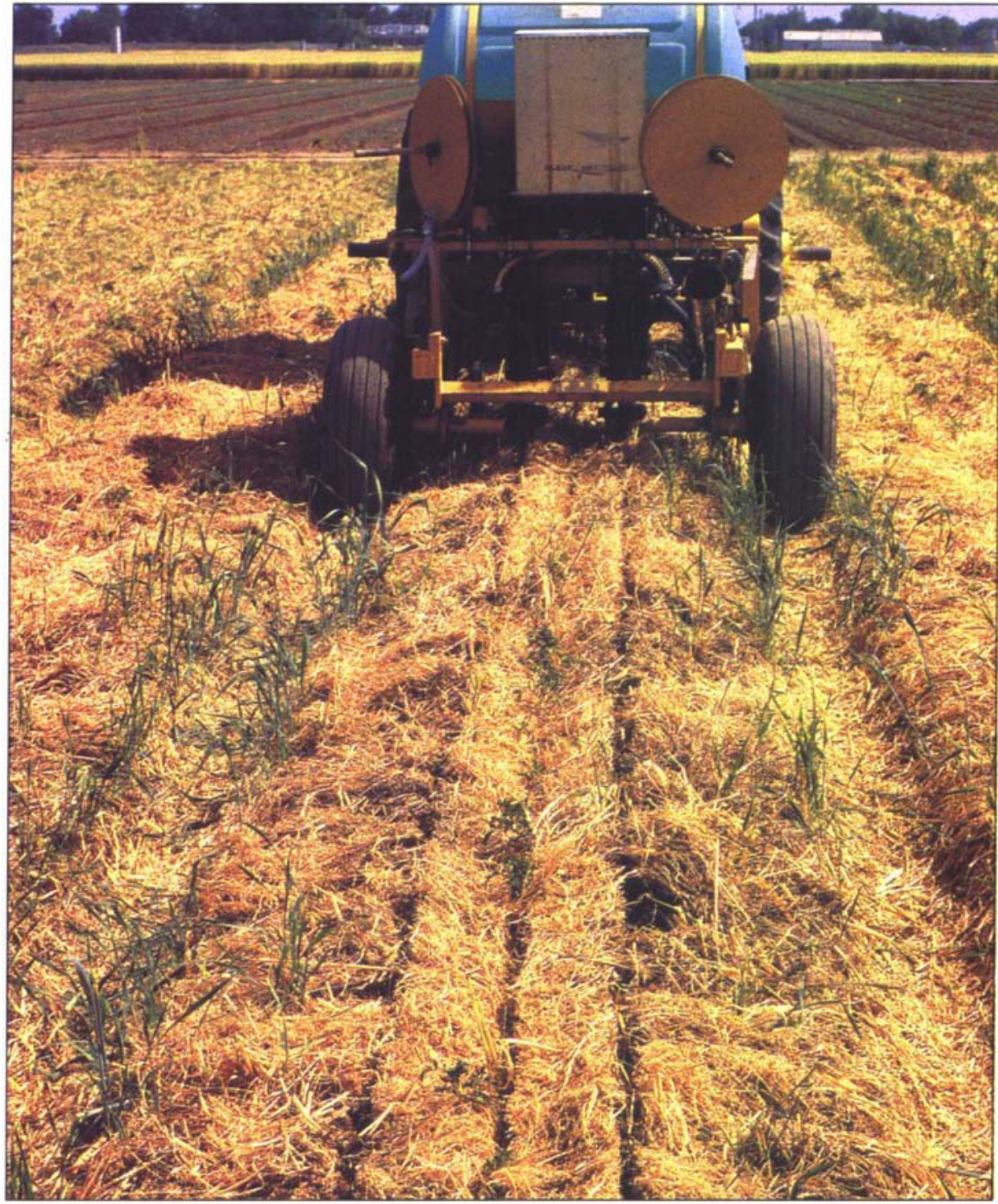

Transplanting tomatoes into cover crop mulch residue in Five Points.

\title{
Soil properties change in no-till tomato production
}

\author{
Enrique V. Herrero a Jeffrey P. Mitchell a W. Thomas Lanini ل \\ Eugene M. Miyao $\square$ Ronald D. Morse $\square$ Enio Campiglia \\ Steven R. Temple
}

\begin{abstract}
California's Central San Joaquin Valley (SJV) produces a number of high-value row crops, including many vegetables and cotton. Current cropping practices in this region are characterized by routine fertilizer and irrigation inputs and by intensive tillage. Various aggressive tillage practices and associated losses of soil organic matter have led to recent concerns about degradation of the soil resource in the region (Mitchell
\end{abstract}

et al. 1999a). An important alternative for potentially reducing such degradation, as well as overall production costs, is the use of reduced tillage production practices. Several conservation tillage systems have been developed in recent years, including no-till, strip till and ridge till.

In the southeastern United States, the use of cover crop mulches in no-till systems has been proposed as a means to sustain soil quality, reduce soil erosion and add organic matter to the soil (Abdul-Baki and Teasdale 1993). Notill production systems are currently being evaluated there for a number of row crops. Warmer winters, drier summers and a longer growing season are distinctive climatic characteristics that make California's SJV quite different from the southeastern United States. The extent to which no-till production may be appropriate for Cali- 
fornia is unknown. Large-scale farms that dominate the landscape in the SJV currently rely on the use of equipment developed to operate on bare soil. Effects of no-tillage practices on water movement and infiltration in SJV production systems may also present barriers to potential adoption of this technology that have not been encountered in the southeast. However, increased water conservation under no-till systems due to reduced evaporative losses and increased infiltration may result in benefits that are singularly attractive to Central SJV producers.

Improvement of rainwater capture and infiltration have been attributed to reduced surface crusting and slower water movement on the soil surface due to plant residues in no-till conditions in rainfall simulation trials (Griffith et al. 1986). This may be critical to crop success in rain-fed production environments. In California, the absence of summer rainfall necessitates the use of irrigation for crop production during this season. Plant residues on the soil surface may also reduce evaporative losses in SJV row crop production systems and thereby increase water conservation, provided that furrow irrigation can be efficiently accomplished. A significant limitation to the adoption of cover-crop-driven systems in summer-irrigated row crop production regions has been difficulty in conserving adequate soil moisture during the period of spring cover-crop incorporation to permit germination of the following cash crop. Surface mulch cover crops that are not incorporated into the soil might conceivably relieve this limitation.

An additional problem that may offset the potential benefits of surface mulches in conserving soil moisture is the water used during the off-season time when cover crops are growing (Mitchell et al. 1999b). This may necessitate additional irrigations of a noncash crop, increase the overall cost and limit possible adoption of the system. However, the impacts of off-season cover crops on soil water storage in semiarid regions such as the SJV are not well documented. The objectives of this research were to assess the abil- ity of no-till systems in conserving soil moisture and improving water infiltration under furrow irrigation conditions.

\section{Triticale and rye treatments}

This study was part of a larger notill processing tomato production experiment conducted at the UC West Side Research and Extension Center in 1997 and 1998 (Herrero et al. 2001). Two grass/legume mixtures - triticale/lana woolypod vetch $(X$ Triticosecale Wittm. / Vicia dasycarpa Ten.) (triticale) and rye/ lana woolypod vetch (Secale cereale L./ $V$. dasycarpa Ten.) (rye) - were used as cover crop mulches in no-till treatments. We compared these treatments with a winter fallow treatment with preplant herbicide (fallow $+h$ ) and a fallow control treatment with no herbicide (fallow-h) at three different springtime-applied nitrogen fertilization rates $(\mathrm{N} 0=0, \mathrm{~N} 1=100$ and $\mathrm{N} 2=$ $200 \mathrm{lb} / \mathrm{acre}$ ). Cover crops were sown in October 1996 on the top of preshaped 60-inch center-to-center beds, killed in March 1997 and left lying on the beds as a mulch. Processing tomato ('Halley 3155 ') seedlings were transplanted in a single row at 9.5-inch distance between plants in April 1997 and sprinkle irrigated during the first 6 weeks after transplanting. Thereafter, the crop was furrow irrigated until 3 weeks before harvest. The study was repeated in the same plots in 1998 with similar management. Soil properties and the water relations of three of these treatments were characterized and are reported here.

\section{No-till effects}

Soil water content. Changes in soil water content were monitored with neutron hydroprobe during July 1997 in the fallow $+\mathrm{h}$ and triticale plots, and from October 1997 through August 1998 on the fallow $+h$, triticale and rye systems. Two PVC access tubes were
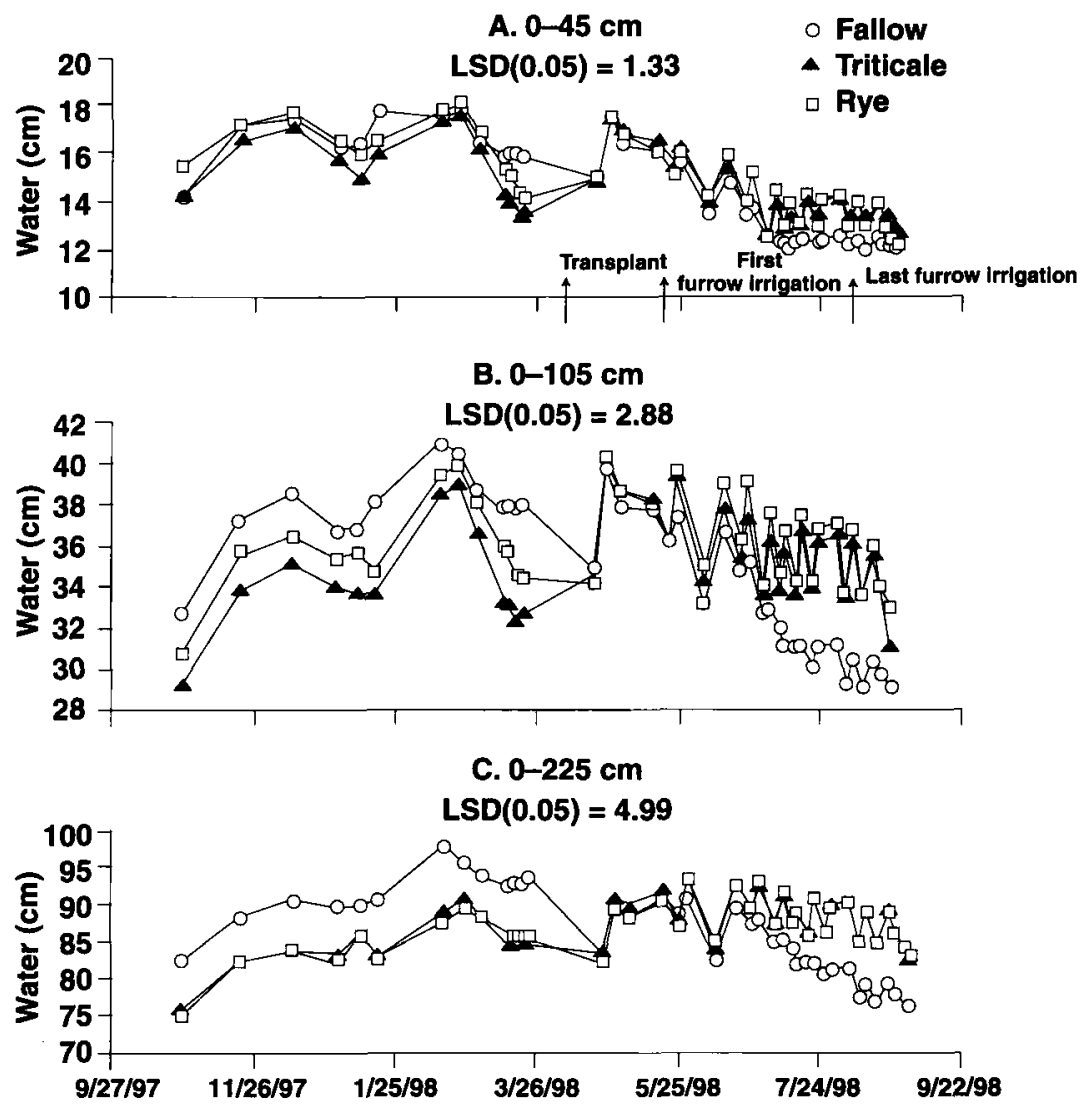

Fig. 1. Changes in average volumetric soil water content, fall 1997 to fall 1998, for (A) 0 to $45 \mathrm{~cm}$ (0 to 18 inch); (B) 0 to $105 \mathrm{~cm}$ (0 to 42 inch); and (C) 0 to $225 \mathrm{~cm}$ (0 to 90 inch) depths. 


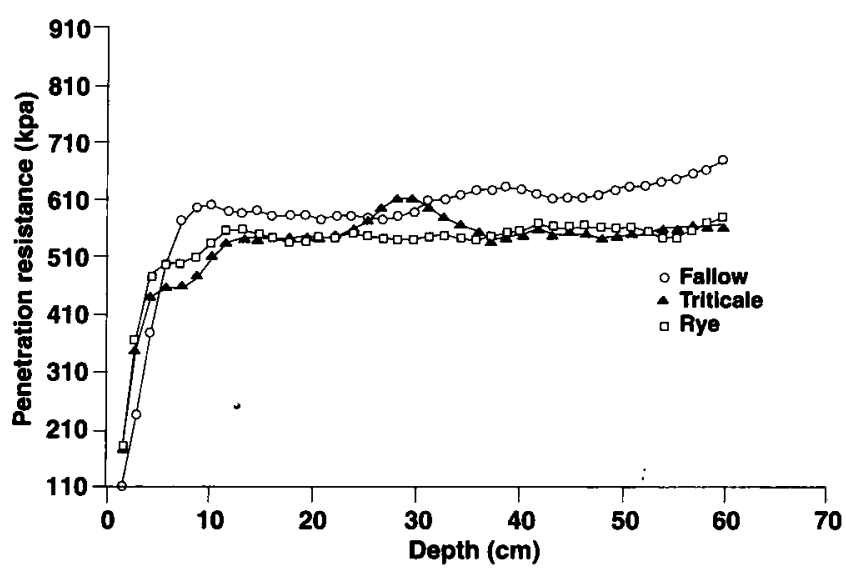

Fig. 2. Effect of no-till triticale and rye mulches and fallow standard tillage systems on soil penetration resistance from 0 to $60 \mathrm{~cm}$ (0 to 2 feet).

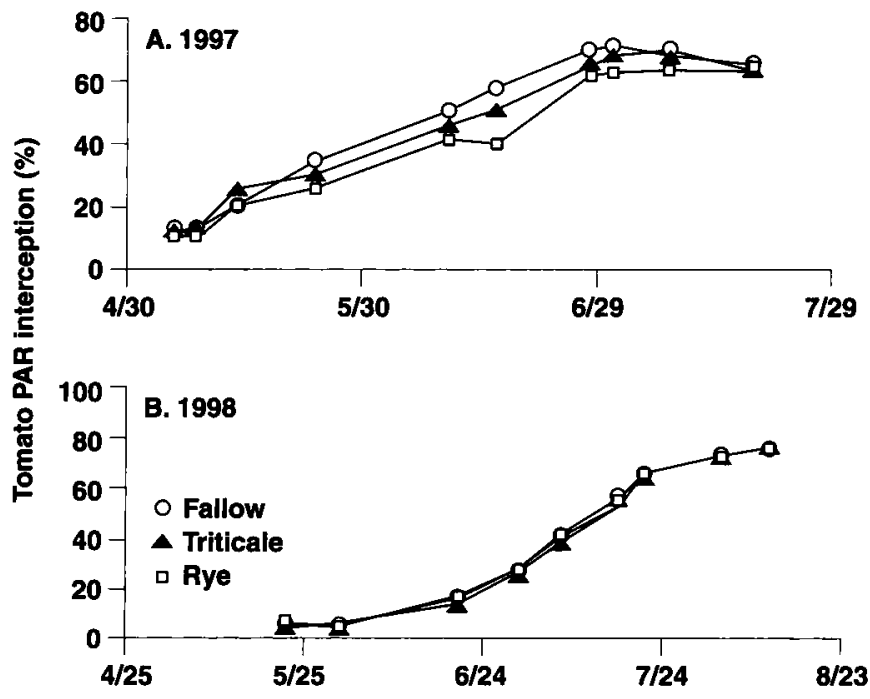

Fig. 3. Tomato canopy interception of photosynthetically active radiation (PAR) by tomatoes in triticale and rye mulch and fallow plots in (A) 1997 and (B) 1998. No significant differences were found in either year at the 0.05 level.

placed in the seed line of each bed, and hydroprobe counts were taken every foot to 6 feet in 1997 and to 7 feet from fall 1997 to fall 1998.

During 1997, soil water content between 0 and 78 inches did not differ among treatments (data not shown). Soil water content during the 1997 1998 winter tended to be higher under the fallow $+h$ than the cover crop treatments until cover crop termination (fig. 1). Soil water content of cover crop treatments in shallower soil layers (18 and 42 inches) was significantly lower than fallow treatments at the end of the winter as temperatures rose and cover crop growth accelerated (fig. 1A and 1B). During the 1998 tomato crop season, soil water content between 0 and 90 inches was greater under the triticale and the rye mulches than the fallow $+h$, beginning the third week after furrow irrigations were started (fig. 1C).

Soil moisture in the shallower layers was also affected by cover crop mulches. In the 42-inch depth increment, there was significantly higher water content under the cover crops than under the fallow $+h$ from about 1 month after the first furrow irrigation until 2 weeks before the last irrigation. Changes in soil water content during the cycle of furrow irrigation events under the fallow $+h$ appeared to be less pronounced than under the triticale or rye surface mulch. This can be easily seen in the trend of water content during July 1998 , when changes in soil water content for 18-inch depth under fallow $+\mathrm{h}$ are characterized by a relatively flat line, while rye and triticale showed a marked increase just after each irrigation (fig. 1).

Soil compaction. A Rimik penetrometer with a 0.25 square-inch $30^{\circ}$ cone was used for recording soil strength at 0.6 -inch intervals to a soil profile depth of 2 feet. We made 32 penetrometer insertions per plot 3 days after a sprinkler irrigation in the fallow $+h$, triticale and rye treatments in August 1998. Although soil compaction in the fallow $+h$ treatment tended to be higher than under the cover crop mulches for most of the 0.6 -inch intervals, especially below 1 foot, differences were significantly higher only for the 3, 3.6, 4.2, 17, 18 and 24 inch depths, but lower from the surface to 2.4 inches (fig. 2).

Earthworms. We estimated the number of earthworms in the surface 6 inches of soil in March 1998 by placing a 16.5-inch-diameter cylinder at two locations on the center of each plot, 30 minutes after applying a dilute mustard powder solution, which caused the earthworms to surface. Earthworms numbers were significantly different among tillage/mulch treatments. A mean of 2.1 earthworms per square foot was found in no-till treatments compared to a mean of 0.6 earthworms per square foot in fallow plots.

Carbon. Eight 0- to 0.6-inch subsamples of soil per plot were collected, air dried for 48 hours, ground and submitted to the UC Davis DANR Lab for determination of total carbon in September 1998, at the end of the second no-till season. Soil carbon was significantly higher (by $14 \%$ and $8 \%$ under triticale and rye, respectively) relative to fallow $+\mathrm{h}(0.62 \%, 0.72 \%$ and $0.66 \%$ in fallow $+h$, triticale and rye, respectively; $p 35=0.0012$ ).

Tomato canopy growth. Tomato plant growth was assessed by measuring the photosynthetically active radiation intercepted by the canopy using a Decagon Ceptometer. Light interception readings were taken at midday from three different randomly selected points in each plot every 7 days; 10 times in 1997 and 18 times in 1998, starting on May 6 and May 22, respectively. Tomato canopy growth did not reach $100 \%$ cover in either 1997 or 1998 (fig. 3). Tomato plant growth in the triticale and rye plots did not differ from the fallow+h system in either 1997 or 1998.

\section{Soil water storage}

These experiments confirm findings from other reports (Hoyt et al. 1994) suggesting that the use of surface mulches enhances water conservation in the soil profile. Generally this improvement has been attributed to re- 
duced evaporative losses due to lower soil temperatures under residues. If reduced evaporative losses were the only reason for greater soil water conservation, then we might expect no differences in soil water content immediately after irrigation events that apply enough water to bring all treatments back to field capacity. However, our data show that differences in soil water content were actually higher after each furrow irrigation than in the middle of an irrigation cycle (fig. 1). A combination of reduced evaporative losses and increased lateral water infiltration across the bed under surface mulches may explain this finding.

Direct evaporation from the soil is a three-phase process. During the first phase, following wetting, evaporation is limited only by the energy available at the soil surface. The second phase, the soil limiting phase, begins when the soil cannot supply water fast enough to match radiative demand and evaporation is progressively reduced. During the third phase, evaporation is very slow because it depends on temperature gradients to drive water vapor flows in the soil. Evaporative losses are therefore important mainly during the first phase. We postulate that changes in soil properties rather than the energy available at the soil surface resulted in differences in soil water content between treatments in this comparison of no-till and standard till systems.

Soil temperatures in fallow plots were significantly higher than under triticale during the sprinkle irrigation phase (fig. 4), but there were not any differences in soil water content at that time (fig. 1). The fact that changes in soil water content started with the shift in irrigation system supports our contention that lateral infiltration of furrow irrigation water was improved under the no-till system.

During the period of sprinkler irrigation in our study, conditions for evaporation were ideal: high moisture availability at the soil surface; higher temperatures in the fallow soil relative to the mulch soils; and low crop canopy development. However, differences in soil water content between the cover crop mulches

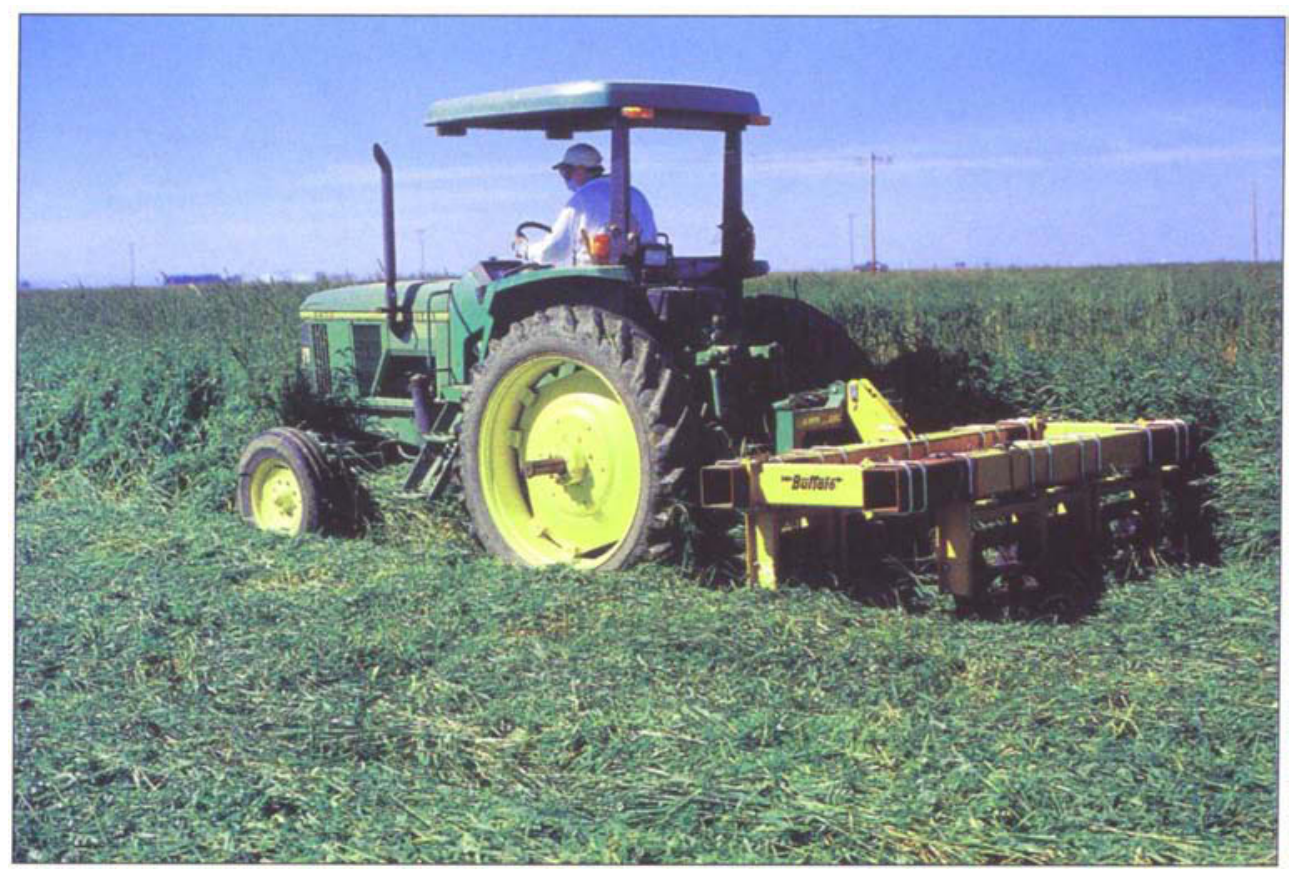

Chopping triticale/vetch cover crop with a Rolling Stalk Chopper.

and the fallow plot were not apparent until furrow irrigation started. Transpiration, rather than evaporation, is the main mechanism for water loss in fully developed crop canopies, and radiation interception by a canopy is the only factor limiting transpiration (Hsiao 1993). However, differences in transpiration between treatments do not explain why there was less water in the fallow plots, since radiation interception was similar in these treatments to that in the triticale and rye plots (fig. 3).

The fact that there were more earthworms under mulch treatments means not only an increase in soil biological activity, but also the presence of openings in the soil that could improve water infiltration. Although bulk density often tends to be higher under no-till, and there is frequently more air-filled porosity in plowed relative to no-till soils, Gantzer and Blake (1978) observed more macropores (soil pores larger than $1 \mathrm{~mm}$ ) in no-till soils relative to plowed soils. The importance of macropores in water infiltration has been shown by Thomas and Phillips (1979).

Penetrometer measurements in our experiment indicated that mulches tended to reduce soil compaction below 1 foot (fig. 2). These lower soil strength values were found at the same depth interval that contributed the most in terms of differences in water content between cover crop and fallow plots. In addition, careful observation of the reported standard error values for our penetrometer data indicates higher variation in the cover crop relative to the fallow treatments. This greater heterogeneity in soil strength under no-till mulches may be attributed to the presence of root channels
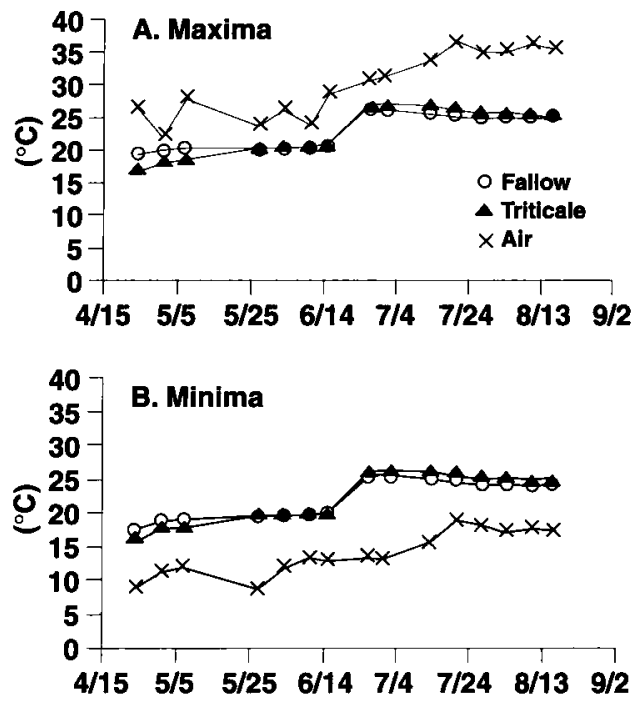

Fig. 4. Effect of no-till triticale mulch and fallow standard tillage systems on soil temperature: (A) air and soil maxima and (B) air and soil minima $\left({ }^{\circ} \mathrm{F}=1.8\left({ }^{\circ} \mathrm{C}\right)+32\right)$. Data are weekly averages during tomato growing season. 


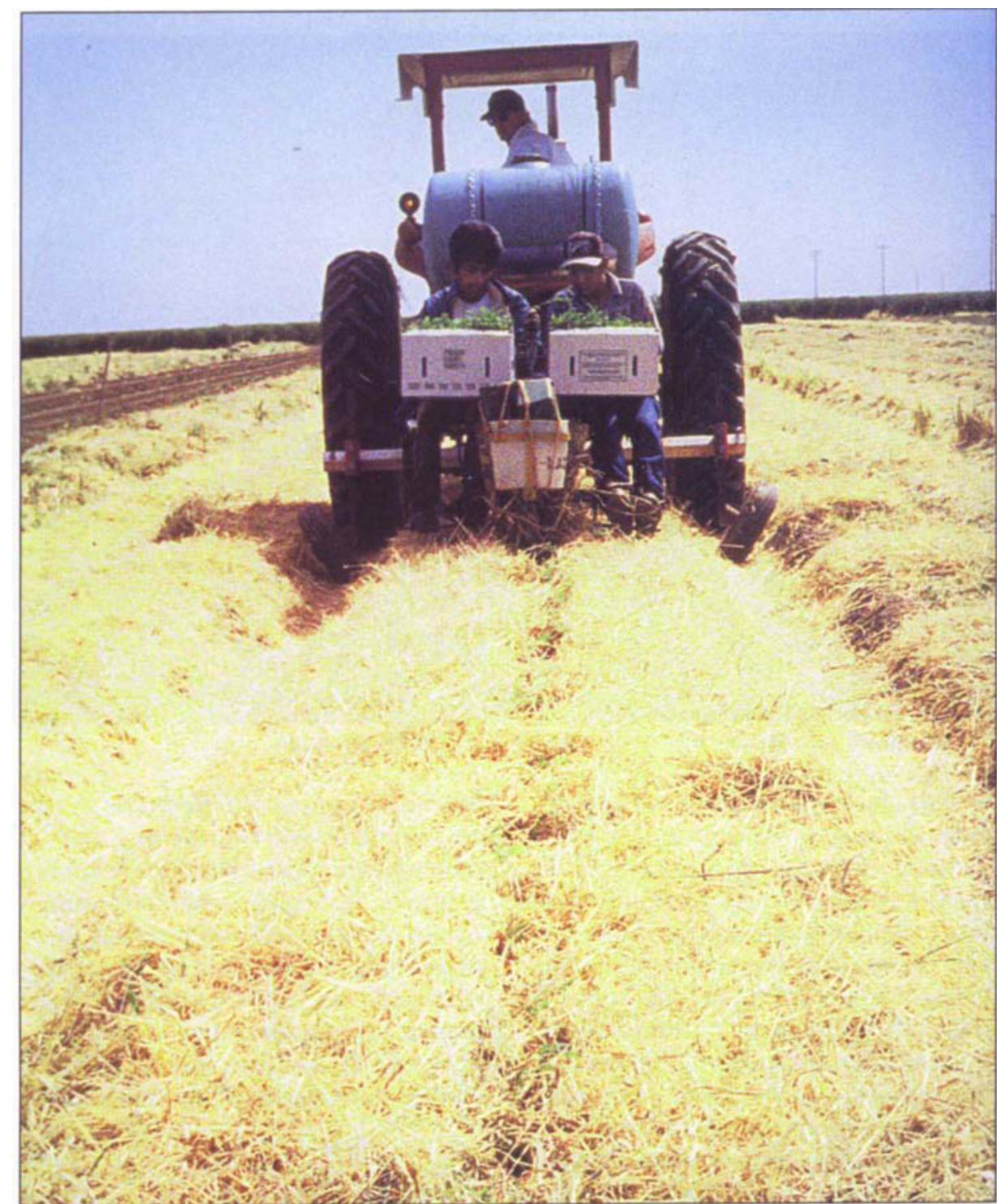

Sidedressing fertilizer into cover crop surface mulch in no-till processing tomato production system.

or earthworm burrows in these plots (fig. 2).

The enhanced infiltration that our data show could probably be a means for conserving more water that otherwise would be lost by surface runoff or evaporation. Other aspects of cover crops need to be taken into account, however, when evaluating these alternative systems. Soil moisture depletion by cover crops grown off-season may be a problem for subsequent crops that rely on stored moisture for seedling emergence and initial growth during early spring. Although our measurements indicate that cover crops consumed more water relative to the fallow plots during the last part of the winter, we have not yet evaluated the full potential impact of this aspect of mulch systems. However, this is a very important dimension of our ongoing work. Another potential benefit of the surface mulch alternative might be to shorten the period between cover crop termination and initiation of the subsequent cash crop, because incorporation and bed reshaping would not be needed.

In summary, furrow irrigation may not be a limitation to the potential adoption of no-till practices in California, provided that furrows are swept clean, as was done in this study. Water infiltration was actually enhanced by the no-till mulch system. In years when winter rainfall is low, however, increased soil water depletion by a cover crop may become a more significant potential limitation for this sys- tem. Other factors, including the need to time more spring field operations, cooler soil temperatures, and the cost of new equipment that may be required, as well as weed management, are components of no-till mulch systems that require considerable further evaluation and innovation.

E.V. Herrero is Postgraduate Researcher, Department of Vegetable Crops, UC Davis and UC Cooperative Extension, SutterYuba Counties; J.P. Mitchell and W.T. Lanini are Extension Specialists, Department of Vegetable Crops and Weed Science, UC Davis; S.R. Temple is Extension Specialist, Department of Agronomy and Range Science, UC Davis; E.M. Miyao is Farm Advisor, Yolo and Solano Counties, R.D. Morse is Professor of Horticulture, Virginia Polyteclinic Institute and State University in Blacksburg, Virginia; and E. Campiglia is Researcher, Department of Crop Production, University of Tuscia, Viterbo, Italy. Funding for this project was provided by the UC Sustainable Agriculture Research and Education Program, the California Tomato Research Institute and the California Tomato Commission.

\section{References}

Abdul-Baki AA, Teasdale JR. 1993. A notillage tomato production system using hairy vetch and subterranean clover mulches. Hort Science 28:106-8.

Gantzer CJ, Blake GR. 1978. Physical characteristics of Le Sueur clay loam soil following no-till and conventional tillage. Agron $\mathrm{J}$ 70:853-57.

Griffith DR, Mannering JV, Box JE. 1986. Soil and water management with reduced tillage. In: Sprague MA and Triplett GB (eds.) No-Tillage and Surface Tillage Agriculture. New York: Wiley. p 19-55.

Herrero EV, Mitchell JP, Campiglia E, et al. 2001. Use of cover crop mulches in furrow irrigated no-till processing tomato production system. Hort Technology 11(1):43-8.

Hoyt GD, Monks DW, Monaco TJ. 1994. Conservation tillage for vegetable production Hort Technology 4(2):129-35.

Hsiao TC. 1993. Effects of drought and elevated $\mathrm{CO}_{2}$ on plant water use efficiency and productivity. In: Jackson MB and Black CR (eds.). Interacting Stresses on Plant in a Changing Climate. NATO ASI Series, Vol. 16. Berlin: Springer-Verlag. p 446-59.

Mitchell JP, Hartz T, Pettygrove S, et al. 1999 a. Organic matter recycling varies with crops grown. Cal Ag 53(4): 37-40.

Mitchell JP, Peters DW, Shennan C. $1999 b$. Changes in soil water storage in winter fallowed and cover cropped soils. J. Sust Agr Vol. 15(2/3):19-31.

Thomas GW, Phillips RE. 1979. Consequences of water movement in macropores J Environ Qual 8(2): 149-52. 